\title{
A systematic review on anti-Alzheimer's disease activity of prescription Kangen-karyu
}

\author{
Pradeep Paudel $^{1,2}$, Chan Hum Park ${ }^{3}$, Hyun Ah Jung ${ }^{4}$, Takako Yokozawa ${ }^{5, *}$, Jae Sue Choi ${ }^{1, *}$ \\ ${ }^{1}$ Department of Food and Life Science, Pukyong National University, Busan, Republic of Korea; \\ ${ }^{2}$ National Center for Natural Product Research, The University of Mississippi, Oxford, USA; \\ ${ }^{3}$ Department of Medicinal Crop Research, National Institute of Horticultural and Herbal Science, Rural Development Administration, Eumseong, \\ Republic of Korea; \\ ${ }^{4}$ Department of Food Science and Human Nutrition, Jeonbuk National University, Jeonju, Republic of Korea; \\ ${ }^{5}$ Graduate School Science and Engineering for Research, University of Toyama, Toyama, Japan.
}

SUMMARY Traditional Chinese and Japanese medicines have become prime sources of drug discovery and there is a pressing need to investigate the effectiveness of these traditional medicines for modern drug discovery. Recently, among various traditional formulations, studies on Kangen-karyu (GuanYuan-Ke-Li), a mixture of six medicinal herbs (Salviae Miltiorrhizae Radix, Cnidii Rhizoma, Paeoniae Radix, Carthami Flos, Aucklandiae Radix, and Cyperi Rhizoma), have been growing to assess its neuroprotective role. This prompted us to undertake a thorough review of various targets of Kangen-karyu regarding its effectiveness against Alzheimer's disease, particularly focusing on cholinesterases, beta-site amyloid precursor protein cleaving enzyme 1, and glycogen synthase kinase $3 \beta$. This review provides new insights into Kangen-karyu medication as a prospective antiAlzheimer's medication and indicates the need for in-depth in vivo investigation in the future.

Keywords Kangen-karyu, Alzheimer's disease, cholinesterase, BACE1, GSK3 $\beta$

\section{Introduction}

With an increase in the elderly population in developing countries, the prevalence of Alzheimer's disease (AD) is rapidly increasing (1). Thirty-six million people suffer from $\mathrm{AD}$ worldwide and almost $50 \%$ of the cases of dementia are due to AD (2). Therefore, AD has become a major health problem and an economic burden for health systems. It is characterized by the occurrence of extracellular amyloid plaque deposits and neurofibrillary tangles of the microtubule-binding protein tau in the central nervous system $(3,4)$, and clinical symptoms include compromised memory as well as cognition, orientation, and several emotional disturbances (5).

$\mathrm{AD}$ is a complex neuronal disease involving various factors. Although the exact etiology is still unclear, studies on the $\mathrm{AD}$ brain and $\mathrm{AD}$ animal models have proposed several hypotheses regarding AD: (a) Cholinergic hypothesis - loss of cholinergic neurotransmission in the cerebral cortex due to an increase in cholinesterase activity and degeneration of cholinergic neurons in the basal forebrain deteriorate cognition (6,7). (b) Amyloid hypothesis - proteolytic cleavage of the amyloid precursor protein (APP) by secretases forms amyloid-beta $(A \beta)$ fibrils, and the accumulated $A \beta$ amyloid fibrils develop into senile plaque, causing neurotoxicity, tauopathy, neuronal cell death, and neurodegeneration $(8,9)$. (c) Tau hypothesis - tau is a microtubule-associated protein in axons that regulates the stability of tubulin assemblies; however, aggregation in a hyperphosphorylated state impairs axons of neurons (tauopathy) $(10,11)$. (d) Glycogen synthase kinase $3 \beta$ (GSK3 $\beta$ ) hypothesis - hyperactive GSK3 leads to tau hyperphosphorylation, increased $\mathrm{A} \beta$ production, and memory impairment $(12,13)$. Therefore, since there are several causes of AD, traditional Chinese medicine (TCM) or its combination therapy with various medicinal properties rather than a single agent mostly used in current $\mathrm{AD}$ therapy has the potential to be an effective treatment for $\mathrm{AD}$.

TCM has been widely used in China for thousands of years. Recently, TCM has established its position in the Western world. Some TCM have been reported to be either ineffective or lethal due to hepatotoxicity at higher concentrations or herb-drug interactions (14). However, the majority of TCM, through controlled clinical trials, have been proven to be safe and effective (15). Herein, we systematically reviewed anti-AD activity of a herbal mixture Kangen-karyu (Guan- 
Yuan-Ke-Li in Chinese has been developed in Japan via partial modification of the herbal constituents of the Chinese herbal prescription Guan-Xin No. 2), and its individual components (Salviae Miltiorrhizae Radix, Cnidii Rhizoma, Paeoniae Radix, Carthami Flos, Aucklandiae Radix, and Cyperi Rhizoma), particularly focusing on cholinergic, amyloid, tau, and GSK3 $\beta$ hypotheses of AD treatment. We also discuss in vivo studies on Kangen-karyu and its safety, highlighting its potential in neuronal drug discovery.

\section{Cholinesterases as molecular targets of Kangen- karyu}

Acetylcholine $(\mathrm{ACh})$ is a neurotransmitter of all cholinergic neurons in the central and peripheral nervous systems that modulates neural functions in attention, learning, memory, stress responses, wakefulness and sleep, and responses to sensory information (16). Cholinergic neurotransmission relies on ACh synthesis, storage, transportation, and degradation. Acetylcholinesterase (AChE) is an enzyme responsible for $\mathrm{ACh}$ degradation via hydrolysis to acetate and choline. It is one of the most kinetically efficient enzymes because each molecule can hydrolyze 5,000 molecules of $\mathrm{ACh} / \mathrm{second}$ (17). So, it is a highly effective therapeutic target for symptomatic relief in $\mathrm{AD}$ patients because cholinergic deficit is a consistent finding in early AD.

Impairment of brain $\mathrm{AChE}$ levels in diabetes is one of the reasons for diabetes-associated cognitive decline (18). In a previous study, dried powder of a boiled water extract of Kangen-karyu attenuated cognitive deficit in diabetic mice (19). Furthermore, the study was conducted in vivo using a cognitive deficit-diabetic mouse model by performing behavioral experiments, and evaluating the cholinergic marker protein choline acetyltransferase (ChAT) and muscarinic acetylcholine $\left(\mathrm{M}_{1}, \mathrm{M}_{3}\right.$, and $\left.\mathrm{M}_{5}\right)$ receptors in the hippocampus (19). In a behavioral study, 18-week-old $d b / d b$ mice with a diabetic insult showed a marked decrease in spatial learning performance in terms of the escape latency compared with the same aged-matched nondiabetic mice. However, daily treatment of $d b / d b$ mice with $200 \mathrm{mg} / \mathrm{kg}$ Kangen-karyu significantly and dose-dependently improved the spatial learning performance of old $d b / d b$ animals in the training test. The administration of $100 \mathrm{mg} / \mathrm{kg} /$ day of Kangenkaryu also led to significant improvement in learning performance compared with a vehicle-treated group. In Western blot analysis, a vehicle-treated old $d b$ / $d b$ group showed significantly lower levels of ChAT, $M_{1}$ receptor, $M_{3}$ receptor, and $M_{5}$ receptor. However, the daily oral administration of Kangen-karyu extract (100 and $200 \mu \mathrm{g} / \mathrm{mL}$ ) led to a significant increase in ChAT, $M_{1}$ receptor, $M_{3}$ receptor, and $M_{5}$ receptor levels. Decreases in levels of ACh, ChAT, and muscarinic and nicotinic ACh receptors are associated with cholinergic hypofunction with cognitive deficits (20-22), and the ability of Kangen-karyu to increase the reduced level of these markers in cognitive deficit mouse models demonstrates a neuroprotective role.

To our knowledge, there have been no reports on cholinesterase inhibition by the component Cnidii Rhizoma. From this component, ferulic acid, sinapic acid, 5-hydroxy ferulic acid, and chlorogenic acid have been reported (23). A previous study reported the effect of sinapic acid on the basal forebrain of an ibotenic acid-treated rat model (24). In that study, treatment of rats with ibotenic acid decreased ACh levels in the parietal and frontal cortices and ChAT activity in the parietal cortex. However, pretreatment of rats with sinapic acid (3 and $10 \mathrm{mg} / \mathrm{kg}$ ) reversed the effect of ibotenic acid in a dose-dependent manner. A dose of 10 $\mathrm{mg} / \mathrm{kg}$ of sinapic acid led to significant retention of the ACh levels and ChAT activity in the basal forebrain.

In a study conducted to identify novel AChE inhibitors derived from Salviae Miltiorrhizae Radix (25), two abietane diterpene dihydrotanshinone and cryptotanshinone showed promising inhibition of bovine erythrocyte $\mathrm{AChE}$ with $\mathrm{IC}_{50}$ values of 1.0 and 7.0 $\mu \mathrm{M}$, respectively. However, tanshinone I and tanshinone IIA displayed weak inhibitory effects. Similarly, for human cloned cholinesterase (26), dihydrotanshinone and cryptotanshinone showed mixed non-competitive inhibition of $\mathrm{AChE}$ with $\mathrm{IC}_{50}$ values of 0.89 and 4.67 $\mu \mathrm{M}$, respectively. For human butyrylcholinesterase (BChE), the inhibition mode was uncompetitive with $\mathrm{IC}_{50}$ values of $6.66 \mu \mathrm{M}$ for cryptotanshinone and 5.51 $\mu \mathrm{M}$ for dihydrotanshinone. Also, Wong and colleagues (26) performed molecular docking studies to explore the binding mechanism of these diterpenes with human cloned cholinesterases. In the presence of human AChE, these compounds bound to the active-site gorge lining Trp86, Tyr124, and Tyr337 with different orientations. The penta ring of dihydrotanshinone faced the bottom of the gorge while cryptotanshinone faced the opposite direction - towards the gorge mouth. At the catalytic site, both compounds interacted with the prime catalytic triad residues Ser203 and His447. This suggested that additional interaction of dihydrotanshinone with Tyr337 and Gly120 via $\mathrm{H}$-bonds plays a vital role due to its potency compared with cryptotanshinone. Interestingly, the docking of these diterpenes with hBChE led to a similar binding configuration involving aromatic residues, Trp430, Phe329, and Tyr332.

The crude extract of Paeoniae Radix and its major component, paeoniflorin, were previously reported to have beneficial effects on spatial cognitive deficits caused by the dysfunction of central cholinergic systems and aging in rodents $(27,28)$. Also, in a previous report, an ethanol extract of Paeoniae Radix demonstrated good inhibition of $\mathrm{AChE}$ and $\mathrm{BChE}$ with $\mathrm{IC}_{50}$ values of 25.04 and $10.59 \mu \mathrm{g} / \mathrm{mL}$, respectively (29). 


\section{Beta-site amyloid precursor protein cleaving enzyme 1 (BACE1) as a molecular target of Kangen- karyu}

BACE1 is a type 1 transmembrane aspartyl protease that is involved in the generation of $A \beta$ peptides by neurons through proteolytic cleavage of APP (30). Cleaving of APP by $\beta$-secretase at the $\mathrm{NH}_{2}$-terminus of $\mathrm{A} \beta$ to release a soluble $\sim 100-\mathrm{kD} \mathrm{NH}_{2}$-terminal fragment and a membrane-bound $12-\mathrm{kD} \mathrm{COOH}$-terminal fragment initiates $A \beta$ formation. The progressive formation of insoluble amyloid plaque and vascular deposits of $\mathrm{A} \beta$ peptide is a characteristic event in $\mathrm{AD}(31)$.

The effect of Kangen-karyu on BACE1 activity has yet to be reported. We performed a comparative study on BACE1 inhibition with a boiled water extract of Kangenkaryu and its components (Table 1) (data not published). The boiled water extract of Kangen-karyu demonstrated moderate inhibition. Among the fractions, moderate inhibition was also observed with a boiled water extract of Salviae Miltiorrhizae Radix and Cyperi Rhizoma followed by mild inhibition by Paeoniae Radix, Cnidii Rhizoma, and Carthami Flos. No noticeable inhibition was observed with a boiled water extract of Aucklandiae Radix.

Furthermore, depending upon the activity of individual components of Kangen-karyu, we further studied Salviae Miltiorrhizae Radix. We performed a comparative study on BACE1 inhibition by $\mathrm{MeOH}$ and water extracts of Salviae Miltiorrhizae Radix along with solvent-soluble fractions ( $n$-hexane, $\mathrm{CH}_{2} \mathrm{Cl}_{2}$, EtOAc, $n-\mathrm{BuOH}$, and water fractions) from each extract (data not published). As shown in Table 2, the $\mathrm{MeOH}$ extract of Salviae Miltiorrhizae Radix showed moderate inhibition of BACE1 with an $\mathrm{IC}_{50}$ value of $114.82 \pm 3.00 \mu \mathrm{g} / \mathrm{mL}$. Among the fractions of $\mathrm{MeOH}$ extract, $n$-hexane and $\mathrm{CH}_{2} \mathrm{Cl}_{2}$ fractions showed promising inhibition followed by EtOAc and $n$-BuOH fractions. However, the $\mathrm{H}_{2} \mathrm{O}$ fraction had a mild inhibitory effect. Interestingly, the water extract of Salviae Miltiorrhizae Radix showed good inhibition (Table 3). Among the fractions, the EtOAc fraction demonstrated the most promising inhibition $\left(\mathrm{IC}_{50}\right.$ $=0.20 \pm 0.07 \mu \mathrm{g} / \mathrm{mL})$, followed by $\mathrm{CH}_{2} \mathrm{Cl}_{2}\left(\mathrm{IC}_{50}=6.11\right.$ $\pm 0.53 \mu \mathrm{g} / \mathrm{mL}), n$-hexane $\left(\mathrm{IC}_{50}=11.83 \pm 0.09 \mu \mathrm{g} / \mathrm{mL}\right)$, $n$-BuOH $\left(\mathrm{IC}_{50}=49.32 \pm 2.62 \mu \mathrm{g} / \mathrm{mL}\right)$, and $\mathrm{H}_{2} \mathrm{O}\left(\mathrm{IC}_{50}=\right.$ $64.77 \pm 7.59 \mu \mathrm{g} / \mathrm{mL}$ ) fractions, respectively.

From a structural viewpoint, Salviae Miltiorrhizae Radix comprises water-soluble polyphenolic compounds - danshensu (3, 4-dihydroxyphenyllactic acid), salvianolic acid A, B, and C, protocatechuic aldehyde, and lipophilic compounds - tanshinones. HPLC analysis of a water extract of Salviae Miltiorrhizae Radix revealed tanshinone II and salvianolic acid B as dominant components (32). Because of the complex AD pathology, the neuroprotective components tanshinones and polyphenolics - salvianolic acids might be effective in treating $\mathrm{AD}$ (33). In our previous study (34), we evaluated the BACE1 inhibitory effect of tanshinones and salvianolic acid derivatives from Salviae Miltiorrhizae Radix along with enzyme kinetics and molecular docking simulations. Among the tested compounds, deoxyneocryptotanshinone and salvianolic acid $\mathrm{C}$ exhibited mixed modes of BACE1 inhibition with $\mathrm{IC}_{50}$ values of $11.53 \pm 1.13$ and 9.18 $\pm 0.03 \mu \mathrm{M}$, respectively. Similarly, salvianolic acid A inhibited the enzyme activity competitively with an $\mathrm{IC}_{50}$ value of $13.01 \pm 0.32 \mu \mathrm{M}$. Most of the other tanshinones had moderate inhibitory effects with $\mathrm{IC}_{50}$ values ranging from 30 to $50 \mu \mathrm{M}$. Salvianolic acid A and $\mathrm{C}$ demonstrated higher binding affinity at the active catalytic site of BACE1 involving $\mathrm{H}$-bond interaction with conserved aspartic acid residues Asp228 and

Table 1. BACE1 inhibitory potentials of water extract of Kangen-karyu and its constituents

\begin{tabular}{lc}
\hline Sample & $\mathrm{IC}_{50}$ values $^{\mathrm{a}}$ \\
\hline Kangen-karyu & $77.40 \pm 4.58$ \\
Aucklandiae Radix & $>400$ \\
Carthami Flos & $233.34 \pm 0.05$ \\
Cnidii Rhizoma & $147.09 \pm 0.93$ \\
Cyperi Rhizoma & $91.16 \pm 2.21$ \\
Paeoniae Radix & $143.57 \pm 1.79$ \\
Salviae Miltiorrhizae Radix & $89.84 \pm 1.87$ \\
Quercetin $^{\mathrm{b}}$ & \\
\hline
\end{tabular}

${ }^{\mathrm{a}}$ The $50 \%$ inhibitory concentrations $\left(\mathrm{IC}_{50}, \mu \mathrm{g} / \mathrm{mL}\right)$ are expressed as the mean \pm SD. ${ }^{b}$ Used as positive control. "Values are expressed in $\mu \mathrm{M}$.

Table 2. BACE1 inhibitory potentials of $\mathrm{MeOH}$ extract from Salviae Miltiorrhizae Radix and its various fractions

\begin{tabular}{lc}
\hline Sample & $\mathrm{IC}_{50}$ values $^{\mathrm{a}}$ \\
\hline MeOH extract & $114.82 \pm 3.00$ \\
$n$-Hexane fraction & $11.79 \pm 0.03$ \\
$\mathrm{CH}_{2} \mathrm{Cl}_{2}$ fraction & $12.06 \pm 0.58$ \\
EtOAc fraction & $74.05 \pm 0.64$ \\
$n$-BuOH fraction & $115.79 \pm 9.34$ \\
$\mathrm{H}_{2} \mathrm{O}$ fraction & $>150$ \\
Quercetin $^{\mathrm{b}}$ & $9.26 \pm 0.36^{*}$ \\
\hline
\end{tabular}

${ }^{a}$ The $50 \%$ inhibitory concentrations $\left(\mathrm{IC}_{50}, \mu \mathrm{g} / \mathrm{mL}\right)$ are expressed as the mean $\pm \mathrm{SD}$. ${ }^{b}$ Used as positive control. "Values are expressed in $\mu \mathrm{M}$.

Table 3. BACE1 inhibitory potentials of $\mathrm{H}_{2} \mathrm{O}$ extract from Salviae Miltiorrhizae Radix and its various fractions

\begin{tabular}{lr}
\hline Sample & $\mathrm{IC}_{50}$ values $^{\mathrm{a}}$ \\
\hline $\mathrm{H}_{2} \mathrm{O}$ extract & $17.82 \pm 0.35$ \\
$n$-Hexane fraction & $11.83 \pm 0.09$ \\
$\mathrm{CH}_{2} \mathrm{Cl}_{2}$ fraction & $6.11 \pm 0.53$ \\
EtOAc fraction & $0.20 \pm 0.07$ \\
$n$-BuOH fraction & $49.32 \pm 2.62$ \\
$\mathrm{H}_{2} \mathrm{O}$ fraction & $64.77 \pm 7.59$ \\
Quercetin $^{\mathrm{b}}$ & $9.26 \pm 0.36^{*}$ \\
\hline
\end{tabular}

${ }^{a}$ The $50 \%$ inhibitory concentrations $\left(\mathrm{IC}_{50}, \mu \mathrm{g} / \mathrm{mL}\right)$ are expressed as the mean $\pm \mathrm{SD}$. ${ }^{\mathrm{b}}$ Used as positive control. "Values are expressed in $\mu \mathrm{M}$. 
Asp32. Prime interacting residue (Ser10) was observed for deoxyneocryptotanshinone and salvianolic acid $\mathrm{C}$ at the allosteric site. Oxygen groups of Ser229 and Glu310 interacted with the oxygen $\mathrm{O} 11, \mathrm{O} 12, \mathrm{O} 15$, and $\mathrm{O} 16$ of salvianolic acid B via hydrogen bonding interaction. The oxygen groups $\mathrm{O} 6$ and $\mathrm{O} 15$ of salvianolic acid $\mathrm{C}$ formed two H-bonds with Gly13 while O3, O6, and $\mathrm{O} 7$ interacted with Lys9, Gln304, and Asp318 via hydrogenbonding. These findings reveal that the hydroxyl moieties in salvianolic acids play crucial roles in BACE1 interaction. Structure-activity relationships within caffeic acid derivatives reveal that the phenolic $-\mathrm{OH}$ group has a crucial effect on BACE1 inhibition. Activity was enhanced with an increase in phenolic - $\mathrm{OH}$ groups in rosmarinic acid $\left(\mathrm{IC}_{50}: 29.77 \pm 0.70 \mu \mathrm{M}\right)$ and magnesium lithospermate $\left(\mathrm{IC}_{50} ; 30.35 \pm 2.67 \mu \mathrm{M}\right)$ compared with caffeic acid $\left(\mathrm{IC}_{50} ;>200 \mu \mathrm{M}\right)$. The number of phenolic $\mathrm{OH}$ groups in magnesium lithospermate is higher than in rosmarinic acid; however, the activity was similar. The arrangement of alkoxy groups and presence of magnesium might be responsible for this effect.

\section{GSK3 $\beta$ as a molecular target of Kangen-karyu}

GSK3 is one of the prime targets of AD and is responsible for the generation of paired helical filamentstau, a major component of neurofibrillary tangles in the brain (35). It is a multifunctional proline-directed serine/threonine protein kinase for glycogen synthase phosphorylation involved in diverse biological processes (36). Cumulative evidence identifies glycogen synthase kinase as a potential target for neuroprotection because it contributes to the $\mathrm{AD}$-associated hyperphosphorylation of tau and tau protein as a widely recognized substrate of GSK3 (37). The reduction of aberrant over-activity of this enzyme decreases various aspects of AD pathology (38). Two isomeric forms of GSK, GSK3 $\alpha$ and GSK3 $\beta$, share $98 \%$ homology in the catalytic domain, have similar biochemical properties, and are ubiquitously expressed in cells and tissues. Phosphorylation of serine residue (Ser21 in GSK3 $\alpha$ and Ser9 in GSK3 $\beta$ ) inhibits GSK3 (36).

In our previous study conducted to evaluate anti$\mathrm{AD}$ activity in vitro via the GSK3 enzyme, boiled water extract of Kangen-karyu demonstrated potent inhibition of GSK3 $\beta$ with an $\mathrm{IC}_{50}$ value of $17.05 \pm 1.14 \mu \mathrm{g} / \mathrm{mL}$, as shown in Table 4 (39). Also, water extracts of all individual components showed good inhibition with $\mathrm{IC}_{50}$ values ranging from 7.77 to $93.61 \mu \mathrm{g} / \mathrm{mL}$. Water extract of Salviae Miltiorrhizae Radix showed promising inhibition among the components followed by Cyperi Rhizoma. Other components showed mild inhibition with the following potency order: Paeoniae Radix $>$ Cnidii Rhizome $>$ Aucklandiae Radix $>$ Carthami Flos (Table 4). Polar constituents (rosmarinic acid, magnesium lithospermate B, salvianolic acid A, salvianolic acid B, and salvianolic acid $C$ ) that were reported from water
Table 4. GSK3 $\beta$ inhibitory potentials of water extract of Kangen-karyu and its constituents

\begin{tabular}{lc}
\hline Sample & $\mathrm{IC}_{50}$ values $^{\mathrm{a}}$ \\
\hline Kangen-karyu & $17.05 \pm 1.14$ \\
Aucklandiae Radix & $85.04 \pm 6.32$ \\
Carthami Flos & $93.61 \pm 3.99$ \\
Cnidii Rhizoma & $66.74 \pm 2.05$ \\
Cyperi Rhizoma & $20.68 \pm 2.50$ \\
Paeoniae Radix & $62.51 \pm 1.89$ \\
Salviae Miltiorrhizae Radix & $7.77 \pm 1.38$ \\
Luteolin $^{\mathrm{b}}$ & $2.18 \pm 0.13^{*}$
\end{tabular}

${ }^{\mathrm{a}}$ The $50 \%$ inhibitory concentrations $\left(\mathrm{IC}_{50}, \mu \mathrm{g} / \mathrm{mL}\right)$ are expressed as the mean \pm SEM. ${ }^{b}$ Used as positive control. "Values are expressed in $\mu \mathrm{M}$.

extract of Salviae Miltiorrhizae Radix were tested for GSK $3 \beta$ inhibition. The results demonstrated that these polar constituents inhibited GSK3 $\beta$ with $\mathrm{IC}_{50}$ values ranging from 6.97 to $135.5 \mu \mathrm{M}$. Among them, salvianolic acid B was the most potent ATP-competitive inhibitor of GSK3 $\beta$ with the lowest $\mathrm{IC}_{50}$ value $(6.97 \pm 0.96 \mu \mathrm{M})$. With $\mathrm{IC}_{50}$ values of approximately $30 \mu \mathrm{M}$, salvianolic acid A, salvianolic acid B, and magnesium lithospermate $B$ showed good inhibition followed by the moderate activity of rosmarinic acid $\left(\mathrm{IC}_{50}: 135.35 \pm 4.69 \mu \mathrm{M}\right)$ and mild inhibition by caffeic acid $\left(\mathrm{IC}_{50}: 425.01 \pm 7.61 \mu \mathrm{M}\right)$. Although direct evidence of increased GSK3 activity in $\mathrm{AD}$ at present is still limited, studies have clearly demonstrated upregulated GSK3 expression in the hippocampus (40) and peripheral lymphocytes (41) of AD patients.

\section{Future perspective and conclusion}

Although there are reports on anti-AD activity of some compounds that are contained in either of the six components of Kangen-karyu, a detailed and systematic pharmacological study of Kangen-karyu and its individual components is lacking. Generally, traditional medicines are formulae (a mixture of herbs/herbal components), serving as combination therapy. As such, it is difficult to determine the precise pharmacology of the formulae because they can have multiple targets and might also have multiple actions along with synergistic, additive, and/or antagonistic effects. Owing to this and to search for therapeutics pursuing the 'one drugfits-all' concept, the utility of combination therapy has been highlighted (42). This necessitates in-depth pharmacology of Kangen-karyu for the management of AD.

The present review highlights the possible role of Kangen-karyu in the management of $\mathrm{AD}$ via cholinesterase, BACE1, and GSK3 $\beta$ inhibition.

\section{References}

1. Kalaria RN, Maestre GE, Arizaga R, et al. Alzheimer's 
disease and vascular dementia in developing countries: Prevalence, management, and risk factors. Lancet Neurol. 2008; 7:812-826.

2. Lundkvist J, Halldin MM, Sandin J, Nordvall G, Forsell P, Svensson S, Jansson L, Johansson G, Winblad B, Ekstrand J. The battle of Alzheimer's disease - the beginning of the future unleashing the potential of academic discoveries. Front Pharmacol. 2014; 5:102.

3. Selkoe DJ. Cell biology of the amyloid $\beta$-protein precursor and the mechanism of Alzheimer's disease. Annu Rev Cell Biol. 1994; 10:373-403.

4. Hardy J, Selkoe DJ. The amyloid hypothesis of Alzheimer's disease: Progress and problems on the road to therapeutics. Science. 2002; 297:353-356.

5. Tarawneh R, Holtzman DM. The clinical problem of symptomatic Alzheimer disease and mild cognitive impairment. Cold Spring Harb Perspect Med. 2012; 2:a006148.

6. Bartus RT, Dean RL 3rd, Beer B, Lippa AS. The cholinergic hypothesis of geriatric memory dysfunction. Science. 1982; 217:408-414.

7. Terry AV Jr, Buccafusco JJ. The cholinergic hypothesis of age and Alzheimer's disease-related cognitive deficits: Recent challenges and their implications for novel drug development. J Pharmacol Exp Ther. 2003; 306:821-827.

8. Hardy J. The amyloid hypothesis for Alzheimer's disease: A critical reappraisal. J Neurochem. 2009; 110:11291134.

9. Kametani F, Hasegawa M. Reconsideration of amyloid hypothesis and tau hypothesis in Alzheimer's disease. Front Neurosci. 2018; 12:25.

10. Small SA, Duff K. Linking $A \beta$ and tau in late-onset Alzheimer's disease: A dual pathway hypothesis. Neuron. 2008; 60:534-542.

11. Ittner LM, Götz J. Amyloid- $\beta$ and tau - a toxic pas de deux in Alzheimer's disease. Nat Rev Neurosci. 2011; 12:65-72.

12. Hooper C, Killick R, Lovestone S. The GSK3 hypothesis of Alzheimer's disease. J Neurochem. 2008; 104:14331439.

13. Kremer A, Louis JV, Jaworski T, Leuven FV. GSK3 and Alzheimer's disease: Facts and fiction. Front Mol Neurosci. 2011; 4:1-10.

14. Posadzki P, Watson L, Ernst E. Herb - drug interactions: An overview of systematic reviews. Br J Clin Pharmacol. 2013; 75:603-618.

15. Normile D. The new face of traditional Chinese medicine. Science. 2003; 299:188-190.

16. Ferreira-Vieira TH, Guimaraes IM, Silva FR, Ribeiro FM. Alzheimer's disease: Targeting the cholinergic system. Curr Neuropharmacol. 2016; 14:101-115.

17. Potter PE, Hadjiconstantinou M, Meek JL, Neff NH. Measurement of acetylcholine turnover rate in brain: An adjunct to a simple HPLC method for choline and acetylcholine. J Neurochem. 1984; 43:288-290.

18. Liu YW, Zhang L, Li Y, Cheng YQ, Zhu X, Zhang F, Yin $X X$. Activation of mTOR signaling mediates the increased expression of $\mathrm{AChE}$ in high glucose condition: In vitro and in vivo evidences. Mol Neurobiol. 2016; 53:49724980.

19. Zhao Q, Matsumoto K, Tsuneyama K, Tanaka K, Li F, Shibahara N, Miyata T, Yokozawa T. Diabetes-induced central cholinergic neuronal loss and cognitive deficit are attenuated by tacrine and a Chinese herbal prescription, Kangen-karyu: Elucidation in type 2 diabetes $d b / d b$ mice.
J Pharmacol Sci. 2011; 117:230-242.

20. Bartus RT. On neurodegenerative diseases, models, and treatment strategies: Lessons learned and lessons forgotten a generation following the cholinergic hypothesis. Exp Neurol. 2000; 163:495-529.

21. Schliebs R, Arendt T. The significance of the cholinergic system in the brain during aging and in Alzheimer's disease. J Neural Transm. 2006; 113:1625-1644.

22. Schliebs R, Arendt T. The cholinergic system in aging and neuronal degeneration. Behav Brain Res. 2011; 221:555563.

23. Kato A, Fukutake J, Kizu H, Asano N, Adachi I. Inhibitory effects of Senkyu-chacho-san and Cnidii Rhizoma on catechol- $O$-methyltransferase. J Trad Med. 2004; 21:34-38.

24. Karakida F, Ikeya Y, Tsunakawa M, Yamaguchi T, Ikarashi Y, Takeda S, Aburada M. Cerebral protective and cognition-improving effects of sinapic acid in rodents. Biol Pharm Bull. 2007; 30:514-519.

25. Ren Y, Houghton PJ, Hider RC, Howes MJR. Novel diterpenoid acetylcholinesterase inhibitors from Salvia miltiorrhiza. Planta Med. 2004; 70:201-204.

26. Wong KK, Ngo JC, Liu S, Lin HQ, Hu C, Shaw PC, Wan DC. Interaction study of two diterpenes, cryptotanshinone and dihydrotanshinone, to human acetylcholinesterase and butyrylcholinesterase by molecular docking and kinetic analysis. Chem Biol Interact. 2010; 187:335-339.

27. Ohta H, Ni JW, Matsumoto K, Watanabe H, Shimizu M. Peony and its major constituent, paeoniflorin, improve radial maze performance impaired by scopolamine in rats. Pharmacol Biochem Behav. 1993; 45:719-723.

28. Ohta H, Matsumoto K, Shimizu M, Watanabe H. Paeoniflorin attenuates learning impairment of aged rats in operant brightness discrimination task. Pharmacol Biochem Behav. 1994; 49:213-217.

29. Li Q, Tu Y, Zhu C, Luo W, Huang W, Liu W, Li Y. Cholinesterase, $\beta$-amyloid aggregation inhibitory and antioxidant capacities of Chinese medicinal plants. Ind Crop Prod. 2017; 108:512-519.

30. Vassar R, Bennett BD, Babu-Khan S, et al. $\beta$-Secretase cleavage of Alzheimer's amyloid precursor protein by the transmembrane aspartic protease BACE. Science. 1999; 286:735-741.

31. Glenner GG, Wong CW. Alzheimer's disease: Initial report of the purification and characterization of a novel cerebrovascular amyloid protein. Biochem Biophys Res Commun. 1984; 120:885-890.

32. Yu H, Yao L, Zhou H, Qu S, Zeng X, Zhou D, Zhou Y, Li X, Liu Z. Neuroprotection against $A \beta_{25-35}$-induced apoptosis by Salvia miltiorrhiza extract in SH-SY5Y cells. Neurochem Int. 2014; 75:89-95.

33. Zhang XZ, Qian SS, Zhang YJ, Wang RQ. Salvia miltiorrhiza: A source for anti-Alzheimer's disease drugs. Pharm Biol. 2016; 54:18-24.

34. Yu T, Paudel P, Seong SH, Kim JA, Jung HA, Choi JS. Computational insights into $\beta$-site amyloid precursor protein enzyme 1 (BACE1) inhibition by tanshinones and salvianolic acids from Salvia miltiorrhiza via molecular docking simulations. Comput Biol Chem. 2018; 74:273285.

35. Hanger DP, Hughes K, Woodgett JR, Brion JP, Anderton $\mathrm{BH}$. Glycogen synthase kinase-3 induces Alzheimer's disease-like phosphorylation of tau: Generation of paired helical filament epitopes and neuronal localisation of the kinase. Neurosci Lett. 1992; 147:58-62. 
36. Eldar-Finkelman H. Glycogen synthase kinase 3: An emerging therapeutic target. Trends Mol Med. 2002; 8:126-132.

37. Johnson GV, Bailey CD. Tau, where are we now? J Alzheimers Dis. 2002; 4:375-398.

38. Martinez A, Perez DI. GSK-3 inhibitors: A ray of hope for the treatment of Alzheimer's disease? J Alzheimers Dis. 2008; 15:181-191.

39. Paudel P, Seong SH, Zhou Y, Park CH, Yokozawa T, Jung HA, Choi JS. Rosmarinic acid derivatives' inhibition of glycogen synthase kinase- $3 \beta$ is the pharmacological basis of Kangen-karyu in Alzheimer's disease. Molecules. 2018; 23:2919.

40. Leroy K, Yilmaz Z, Brion JP. Increased level of active GSK-3 $\beta$ in Alzheimer's disease and accumulation in argyrophilic grains and in neurones at different stages of neurofibrillary degeneration. Neuropathol Appl Neurobiol. 2007; 33:43-55.

41. Hye A, Kerr F, Archer N, Foy C, Poppe M, Brown R, Hamilton G, Powell J, Anderton B, Lovestone S. Glycogen synthase kinase- 3 is increased in white cells early in Alzheimer's disease. Neurosci Lett. 2005; 373:14.

42. Drews J. Drug discovery: A historical perspective. Science. 2000; 287:1960-1964

Received April 6, 2020; Revised April 15, 2020; Accepted April 19, 2020

*Address correspondence to:

Dr. Takako Yokozawa, Graduate School of Science and Engineering for Research, University of Toyama, 3190 Gofuku, Toyama 930-8555, Japan.

E-mail: yokozawa@inm.u-toyama.ac.jp

Dr. Jae Sue Choi, Department of Food and Life Science, Pukyong National University, Busan 48513, Republic of Korea.

E-mail: choijs@pknu.ac.kr

Released online in J-STAGE as advance publication April 24, 2020. 